\title{
The relationship between SCI editorial board representation and university research output in the field of computer science: A quantile regression approach
}

\author{
Xing Wang ${ }^{1,2}$ \\ ${ }^{1}$ School of Information Management, \\ Shanxi University of Finance \& Economics, \\ 696 Wucheng Road, Taiyuan, P. R. CHINA \\ ${ }^{2}$ Graduate School of Education, \\ Shanghai Jiao Tong University, \\ 800 Dongchuan Road, Shanghai, P. R. CHINA \\ e-mail: wangxing@sjtu.edu.cn
}

\begin{abstract}
This study uses the quantile regression models to explore the relationship between SCl (Science Citation Index) editorial board representation and research output of universities in the field of computer science. Quantile regression allows the investigation of the variation of the relationship between editorial board representation and research output. A total of 447 journals and 14,442 editorial board members were analysed. The results suggest that the number of editorial board members is positively and significantly related to the quantity (number of articles) and impact (total number of citations and citations per paper) of the research output from their respective universities. A deeper analysis using quantile regression, indicates that the relationship between the number of editorial board members and the research output is stronger when the university is at the higher quartile of the conditional research output distribution. In addition, to speculate on possible mechanisms behind the relationship between editorial board representation and research output, two exploratory studies based on two small samples were conducted at the individual and journal level, respectively.
\end{abstract}

Keywords: Editorial board; Gatekeeper; Research output; Quantile regression; Scientometrics; Computer science journals.

\section{INTRODUCTION}

In academia, the editorial board of scholarly journals have an important influence on the quality and relevance of their published research (García-Carpintero, Granadino and Plaza 2010). Editorial boards are important to the entire academic world and there may be some relationship between the editorial board members and the research output of the university. Editorial board members are usually eminent researchers; therefore, they may produce a substantial amount of high impact research for their universities based on their high-level research abilities. Furthermore, editorial board members are considered to be the gatekeepers of journals (Braun and Dióspatonyi 2005a). Therefore, they may have an 
important influence on the research output of universities by controlling academic discourse (i.e. by deciding whether to accept or reject a manuscript).

Several researchers have examined the correlation between university ranking based on editorial board representation and research output. In fact, existing studies have left the following gaps. First, most studies used the number of published articles from each university as an indicator of their research output and compared this number with their number of editorial board members. However, a few studies have used an indicator related to the impact of research output, such as the total number of citations, to measure the research output of the university. Furthermore, citations per paper have not been used in the existing literature. In theory, editorial board members probably obtained their positions because of their high research achievements. Some researchers believe that the number of editorial board members of a given university can reflect the impact of research output of that university (Frey and Rost 2010). Therefore, it may be meaningful to analyse the relationship between universities' editorial board representation and the impact of research output from their universities.

Second, existing studies on the relationship between editorial board representation and research output either calculated correlation coefficients or showed the overlap between the top performers in two types of rankings. However, the overlap between top performers reveal nothing about the medium and low performers. In contrast, the correlation coefficients were focused on the average performers and do not reveal anything about the universities which were in the upper or lower quantile of the conditional distribution of research output. There are differences among universities, and it is possible that the relationship between editorial board representation and research output of universities is different across universities in different parts of the conditional research output distribution. Therefore, showing the overlap between top performers or using standard regression models to draw conclusions may result in an incomplete picture of this relationship. These gaps call attention to the need to study the following two questions:

a) Does a positive and significant relationship exist between a university's editorial board representation and the quantity and impact of its research output?

b) Does the relationship between a university's editorial board representation and its research output differ when the universities are in different parts of the conditional research output distribution?

To answer these questions, the following procedures were conducted. A total of 1573 universities having editorial board member in 447 Science Citation Index (SCl) journals in computer science was selected as the sample. Ordinary least squares (OLS) regression and quantile regression method were used to investigate the relationship between the editorial board representation and the quantity and impact of research output of universities, as well as the variation of the relationship between universities at different parts of the conditional research output distribution. The quantile regression allowed the researcher to examine whether the relationship between editorial board representation and university research output varies when the universities are in different parts of the conditional research output distribution, and furthered our understanding of the relationship between the two. 


\section{LITERATURE REVIEW}

The existing related studies can be classified into three main aspects: (i) the research output of editorial board member, (ii) the relationship between university ranking based on number of editorial board members and research output and (iii) the relationship between country ranking based on number of editorial board members and research output.

\section{The Research Output of Editorial Board Members}

In theory, editorial board members gain their positions because of their high research achievements. Cole and Cole (1973, p.80) have argued that "unless editorial board members are appointed based on their scientific achievements, the academic community might find it difficult to view their authority as legitimate". Many studies have shown that editorial board members produce a substantial amount of high impact research in various disciplines such as nanotechnology (Braun et al. 2007), management (Valle and Schultz 2011), library and information science (Walters 2016; Zhang and Jiang 2015), radiology (Asnafi et al. 2017), and sports medicine (Kay et al. 2017). Although some empirical studies have reported that the research achievements of editorial board members were not as high as expected, such as in the field of social work (Pardeck and Meinert 1999), it has become a mainstream view in academia that editorial board members have high research achievements.

In addition, some researchers have examined whether editorship can increase an editorial board member's research productivity and citations (Bošnjak et al. 2010; Frandsen and Nicolaisen 2011; Langer and Frensch 1999; Luty et al. 2009; Mani et al. 2013; Sugimoto and Cronin 2012; Walters 2015; Wolf et al. 2014). Some studies have shown that editorial board members do not abuse their power to help themselves publish articles in their own journals or to recommend authors to unnecessarily cite their papers, as there is rarely an existence of a flattery citation phenomenon (Bošnjak et al. 2010; Frandsen and Nicolaisen 2011; Mani et al. 2013; Sugimoto and Cronin 2012). However, other studies have shown opposite results (Luty et al. 2009; Levy et al. 2014). For examples, Luty et al. (2009) used 4460 articles published in 20 medical journals within five medical subspecialties to investigate if medical journals prefer to publish articles from their own editorial board members than the members from the rival journal's editorial board. They found that these journals were three times more likely to publish an article from a member of their own editorial board than from a member of the editorial board of a rival journal. Another research by Levy et al. (2014) tested the flattery citation hypothesis which covered 337 editors in top 35 journals of 11 subjects spanning 40 years. Their results showed that the mean citations of the editors were much higher during their editorship period than their pre-editorship period, thus they believed that being an editor can increase one's citations.

\section{The Relationship between University Ranking Based on the Number of Editorial Board Members and Research Output}

Using the number of editorial board members of universities as an evaluation indicator for university ranking is mainly focused on the economics and management disciplines. The earliest study stems from the empirical study by Kaufman in the field of finance (Kaufman 1984). In early studies, a single-dimensional "absolute number of editorial board member" was frequently used as an evaluation indicator for ranking universities. However, with research developments, using the number of editorial board members as an indicator has been continuously elaborated. For example, Gibbons and Fish (1991) included department size as a factor, and used faculty editorial board participation as a percentage of 
department size as an evaluation indicator for ranking the economics faculties of universities in the United States. In addition, Chan and Fok (2003) included the impact of the journal in which the editorial board member served as a factor, and used journal impact factors as a weight to calculate the "number of editorial board members" to globally rank finance departments.

Using the number of editorial board members as an indicator of university ranking is expanding. In fact, an increasing number of sub-disciplines of economics and management, including marketing, international business, and tourism management have introduced university ranking based on number of editorial board members (Chan, Fung and Lai 2005; Frey and Rost 2010; Law, Leung and Buhalis 2010; Urbancic 2005; Urbancic 2011). However, similar studies on disciplines such as science, engineering, agriculture, and medicine remain relatively scarce (Braun et al. 2007). Several researchers have examined the correlation between university ranking based on the number of editorial board members and the research output. Some studies found a positive correlation (Chan and Fok 2003; Frey and Rost 2010; Gibbons and Fish 1991; Kaufman 1984; Urbancic 2005), whereas others did not (Braun et al. 2007; Burgess and Shaw 2010; Chan, Fung and Lai 2005). Hence, there is a lack of convergent results between the studies of various disciplines.

\section{The Relationship between Country Ranking Based on the Number of Editorial Board Members and Research Output}

In the early 1980s, Zsindely, Schubert and Braun (1982) used the number of editorial board members possessed by a country as an evaluation indicator to rank various countries, and examined the correlation between the number of editorial board members from particular countries and the number of articles produced by those countries (the two variables) in eight science disciplines, finding a significant correlation between the two variables. Similar results have been reported by Braun and Dióspatonyi (2005a, 2005b, 2005c), GarcíaCarpintero, Granadino and Plaza (2010), Frey and Rost (2010), and Kumar and Srivastava (2013), who updated Zsindely et al.'s data sample and expanded the empirical discipline for the new millennium.

\section{METHODOLOGY}

\section{Data Collection on Editorial Board Members}

The journals used in this study were from the computer science category of Thomson Reuters's 2011 Journal Citation Reports (Science Edition). This comprises 463 journals serving seven sub-disciplines: artificial intelligence; cybernetics; hardware and architecture; information systems; interdisciplinary applications; software engineering; and theory and methods. The data collection on editorial board members was mainly divided into the following steps :

a) Between January and March, 2013, the researcher first visited the official website of each journal to find their list of editorial board members, indicated by terms such as "Editorial Board". Then, the names and affiliations of the gatekeepers having positions such as editor-in-chief, chief editor, co-editor, deputy editor, associate editor, regional editor, senior editor, editorial board member, or advisory board member were manually collected and stored in an Excel spreadsheet. From the total number of journals, 16 did not specify the names or affiliations of their 
editorial board members. Because it was difficult to obtain the editorial board members' data for these journals, they are excluded from the samples.

b) Data cleaning: The researcher first unified the various names that a university may use. For example, various terms are used to refer to the Swiss Federal Institute of Technology Zurich, including "ETH-Zurich", "Eidgenossische Technische Hochschule Zurich", and "Swiss Federal Institute of Technology Zurich". All of these names were unified according to the standard name defined by the "Organization Enhanced Name" (OG) of the Web of Science to later help facilitate searches for the research output of these universities. The same procedure was performed for other universities. In addition, for universities that have undergone divisions and mergers, the finally determined university listed in the OG of the Web of Science was used as the sample university.

c) The "Subtotal" function in Excel was used to calculate the total number of editorial board members belonging to each institution.

d) The researcher referred to the universities listed in the "Ranking Web of World Universities" published by the Cybermetrics Lab of the Spanish National Research Council (CSIC) and also by Wikipedia to exclude all non-university institutions.

e) Following Gibbons and Fish (1991), if editorial board members were affiliated with multiple universities, their names were counted as many times as they appeared.

Eventually a list of 1,573 universities that are represented in editorial boards, and the number of editorial board members of each university (the 1,573 universities had a total of 14,442 editorial board members) was obtained. These universities constituted the final sample.

\section{Data Collection on Research Output}

To acquire data about the research output of the 1,573 universities, the advanced search section of the Web of Science was used. For example, to obtain the research output of Stanford University, the following search format was used: WC=(COMPUTER SCIENCE ARTIFICIAL INTELLIGENCE OR COMPUTER SCIENCE CYBERNETICS OR COMPUTER SCIENCE HARDWARE ARCHITECTURE OR COMPUTER SCIENCE INFORMATION SYSTEMS OR COMPUTER SCIENCE INTERDISCIPLINARY APPLICATIONS OR COMPUTER SCIENCE SOFTWARE ENGINEERING OR COMPUTER SCIENCE THEORY METHODS) AND OG = (Stanford University). "WC" and "OG" refer to the discipline and name of the organization in Web of Science, respectively. This search format retrieved all papers from Stanford University in these seven sub-disciplines of computer science. Publication type was set as "articles," to limit the analysis to material that had been peer reviewed. In addition, limits were also applied to research output published between 2008 and 2012. Because the stability of editorial board members is remarkably high, that is, the members and their institutions rarely change (Braun and Dióspatonyi 2005a), it is believed that the data on editorial board members and that on research output come from overlapping time periods. Subsequently, the researcher obtained data about the number of articles, total number of citations (citations in 2008-2012 for articles published in 2008-2012), and citations per paper (same as above) for Stanford University by creating citation reports.

The research output data of the remaining 1,572 universities were also obtained using the methods described above. For universities without a corresponding standard name in the OG of the Web of Science, we used "AD" (address) as a substitute for "OG" in the above search format for the initial search, and then refined the search results according to the "institutions" field. 
Moreover, in order to reduce the fluctuations of citations per paper in those universities with a small number of publications and obtain statistically valid and reliable analysis, an arbitrary threshold of 140 articles (which is $10 \%$ of the mean value of the total number of publications produced by the five most productive universities) was used in this study when calculating citations per paper, meaning 502 universities were analyzed for the relationship between the editorial board representation and the citations per paper. The data was collected in May 2013.

\section{Quantile Regression Models}

The main statistical technique used in this study was quantile regression. Traditional OLS regression estimates the mean of the conditional dependent variable distribution as a function of independent variables. In contrast, quantile regression can be used to estimate the various proportions of the conditional dependent variable distribution (e.g. the 30th or 70th percentile).

In this research, estimation of regression models by a quantile regression technique may be preferable to OLS models for the following reasons. First, the OLS models assume a normally distributed dependent variable; this assumption may not apply to our data because of the non-normal character of the citation distribution. This problem is typical in the use of OLS models. In such a case, quantile regression models can be viewed as an effective alternative (Danell 2011). Second, the study included 1,573 universities that were different in many aspects; it was difficult to obtain data for certain variables that might affect the research output in a single subject, such as the research input in a single subject. Generally, in this situation, the effects of the missing variables would likely be relegated to the error term, causing a high probability of existing heteroskedasticity in the model. The existence of heteroskedasticity may lead to differences in the correlation between the editorial board representation and the research output of universities when the universities are located at different quantiles of the conditional distribution of research output. Quantile regression allowed us to explore these differences. Therefore, this method can help us obtain a more complete picture of the relationship between editorial board representation and research output.

The quantile regression model can be written as follows:

$$
\begin{aligned}
& y_{i}=x_{i}^{\prime} \beta_{\theta}+\mu_{\theta i} \\
& \operatorname{Quant}_{\theta}\left(y_{i} \mid x_{i}\right) \equiv \inf \left\{y: F_{i}\left(y_{i} \mid x_{i}\right)\right\}=x_{i}^{\prime} \beta_{\theta} \\
& \operatorname{Quant}_{\theta}\left(\mu_{\theta i} \mid x_{i}\right)=0
\end{aligned}
$$

Where $y_{i}$ represents the dependent variable, while $x_{i}$ is a vector of independent variable; $\beta_{\theta}$ represents the unknown vector of parameters to be estimated; $\mu_{\theta i}$ is the error term; Quant $_{\theta}\left(y_{i} \mid x_{i}\right)$ is the $\theta$ th conditional quantile of $y_{i}$ given $x_{i}$. In our study, the dependent variables were measured by the number of articles, total number of citations and citations per paper respectively; the independent variable was measured as the number of editorial board members affiliated to a university. The value of $\theta$ can vary from 0 to 1 , which represents different quantiles and characterizes the conditional distribution of $y$ given $x$. The quantile regression estimator for $\beta_{\theta}$ is obtained through solving the following problem:

$$
\min \left\{\sum_{i: y_{i} \geq x_{i}^{\prime} \beta_{\theta}} \theta \times\left|y_{i}-x_{i}^{\prime} \beta_{\theta}\right|+\sum_{i: y_{i}<x_{i}^{\prime} \beta_{\theta}}(1-\theta) \times\left|y_{i}-x_{i}^{\prime} \beta_{\theta}\right|\right\}
$$


Equation (2) can be solved by linear programming methods. More on the technical details of quantile regression can be found in Koenker and Bassett (1978). Eviews 6.0 software was used for all statistical analyses.

\section{RESULTS}

\section{Ordinary Least Squares Results}

Table 1 contains the descriptive statistics of the dependent and independent variables selected for this study.

Table 1: Descriptive Statistics of Dependent/Independent Variables

\begin{tabular}{lccccc}
\hline \hline Variable & Mean & SD & Median & Minimum & Maximum \\
\hline \hline Panel A: Dependent variable & & & & & \\
Number of articles & 141.25 & 197.98 & 69.00 & 0.00 & 1803.00 \\
Total number of citations & 566.74 & 928.27 & 233.00 & 0.00 & 9167.00 \\
Citations per paper & 3.94 & 1.27 & 3.78 & 1.30 & 13.74 \\
Panel B: Independent variable & & & & & 1.00 \\
Number of editorial board members & 9.18 & 15.37 & 3.00 & 168.00 \\
\hline \hline
\end{tabular}

First, three OLS models were estimated, for which the results are shown in Table 2. The result suggests that the number of editorial board members is positively and significantly ( $P$ $<0.01$ ) related to the quantity (number of articles) and impact (total number of citations and citations per paper) of the research output from their universities.

Table 2: Results of the OLS Regressions

\begin{tabular}{|c|c|c|c|c|}
\hline & Coeff. & SE & $t$ statistic & $P$ value \\
\hline \multicolumn{5}{|c|}{ Panel A: Dependent variable (number of articles) } \\
\hline Number of editorial board members & $10.623^{*}$ & 0.469 & 22.655 & 0.000 \\
\hline Constant & $43.717^{*}$ & 3.840 & 11.384 & 0.000 \\
\hline F-test & & & \multicolumn{2}{|c|}{$F=3341.631(P=0.000$} \\
\hline White test for heteroskedasticity & & & \multicolumn{2}{|c|}{$\chi^{2}=173.303(P=0.000$} \\
\hline \multicolumn{5}{|c|}{ Panel B: Dependent variable (total number of citations) } \\
\hline Number of editorial board members & $50.369^{*}$ & 2.869 & 17.557 & 0.000 \\
\hline Constant & $104.292^{*}$ & 21.604 & 4.827 & 0.000 \\
\hline F-test & & & \multicolumn{2}{|c|}{$F=3589.267(P=0.000)$} \\
\hline White test for heteroskedasticity & & & \multicolumn{2}{|c|}{$\chi^{2}=422.595(P=0.000)$} \\
\hline \multicolumn{5}{|c|}{ Panel C: Dependent variable (citations per paper) } \\
\hline Number of editorial board members & $0.018^{*}$ & 0.002 & 7.244 & 0.000 \\
\hline Constant & $3.546^{*}$ & 0.077 & 46.007 & 0.000 \\
\hline F-test & & & \multicolumn{2}{|c|}{$F=52.482(P=0.000)$} \\
\hline White test for heteroskedasticity & & & \multicolumn{2}{|c|}{$\chi^{2}=2.273(P=0.321)$} \\
\hline \multicolumn{5}{|c|}{$\begin{array}{l}\text { Note: The standard errors and } t \text { values in the two OLS regression models of the number of editorial } \\
\text { board members on the number of articles and the number of editorial board members on the total } \\
\text { citations are corrected by using the heteroskedasticity-consistent covariance method proposed by } \\
\text { (White 1980). }\end{array}$} \\
\hline
\end{tabular}




\section{Quantile Regression Results}

The White test demonstrated the presence of heteroskedasticity in the two OLS regression models for the number of editorial board members on the number of articles and the number of editorial board members on the total citations (Table 2). Heteroskedasticity was also revealed by the scatter plot of the number of editorial board members and the research output indices. For example, Figure 1 shows that the dispersion of the number of articles increased with the number of editorial board members, which is a typical characteristic of heteroskedasticity. If we trace these divergent trajectories, we could obtain regression lines with different slopes depending on whether we consider the higher quantile (i.e., dotted line R1) or lower quantile (dotted line R2) of the conditional research output distribution, and $R$ is the regression line calculated based on the results of OLS. In other words, the relationship between the number of editorial board members and the research output of universities is different when the universities are in different quantiles of the conditional research output distribution. Considering this feature of the data, to gain a better understanding and to obtain a more complete picture of the relationship between the number of editorial board members and the research output of universities, a quantile regression analysis was conducted.

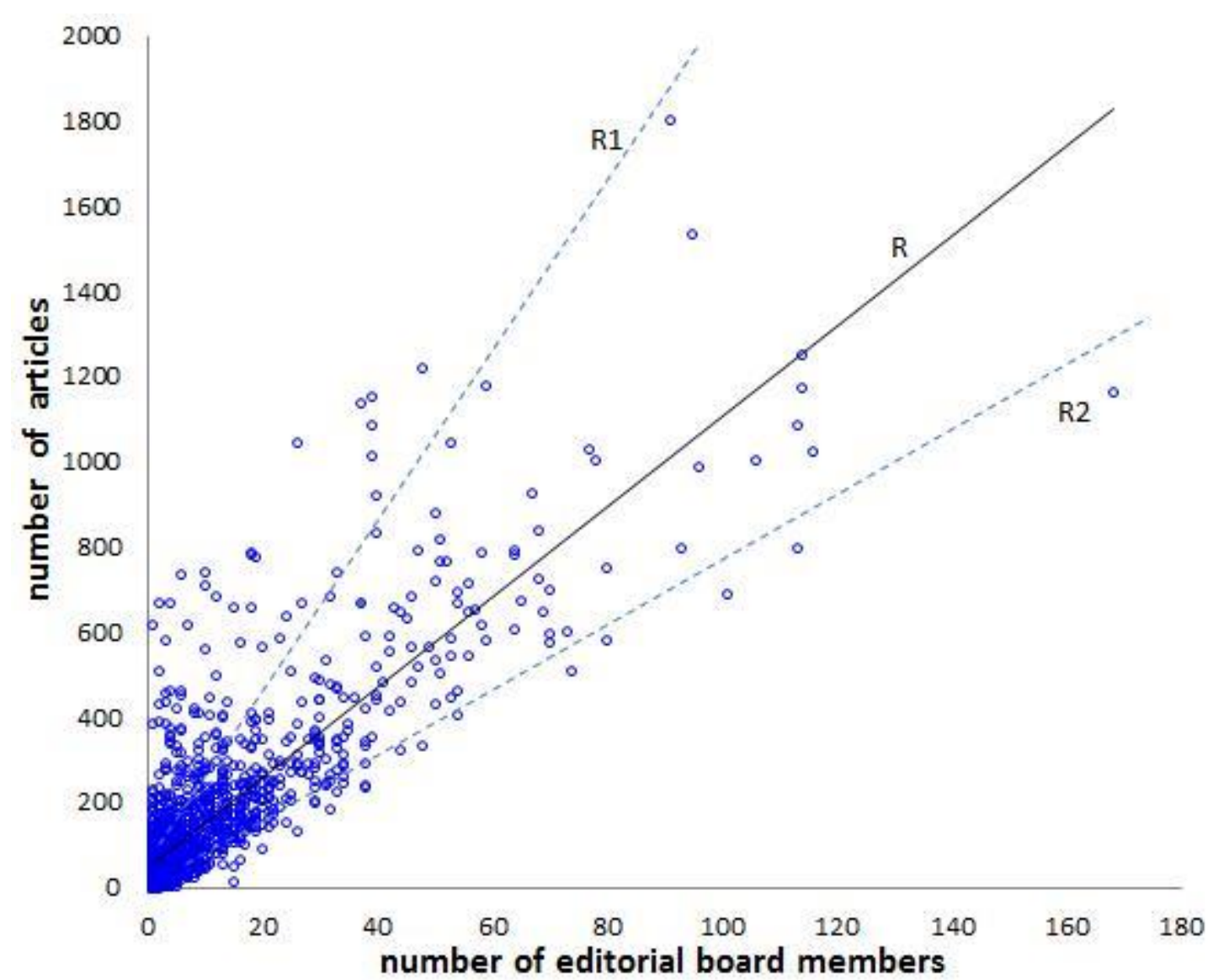

Figure 1: The Heteroskedastic Relationship between the Number of Editorial Board Members and the Number of Articles

The researcher computed 19 quantile regression estimates (5\%-95\%, in 5\% increments). The results are presented in Table 3 (5\%-50\%) and Table 4 (50\%-90\%). 
When considering the relationship between the number of editorial board members and the number of articles, the coefficient was positive and significant at the $5 \%$ level across all quantiles. Furthermore, the magnitude of the coefficient gradually increased from 6.99 at the $5 \%$ quantile to 19.17 at the $95 \%$ quantile. Thus, the quantile regression results indicate that the relationship between the number of editorial board members and the number of articles is stronger (weaker) when the university is at the higher (lower) quantile of the number of articles distribution.

Similar results were obtained for the relationship between the number of editorial board members and the total number of citations. The coefficient was also positive and significant at the $5 \%$ level for all quantiles. In addition, the relationship between the number of editorial board members and the total number of citations is stronger (weaker) when the university is at the higher (lower) quantile of the total number of citations distribution.

When considering the relationship between the number of editorial board members and the citations per paper, the coefficient was positive and significant at the $5 \%$ level for all quantiles. Furthermore, the coefficient of the number of editorial board members shows an overall increasing trend from the lower to the higher quantiles of the citations per paper distribution.

Table 3: Quantile Regression Estimates (Percentiles 5\%-50\%)

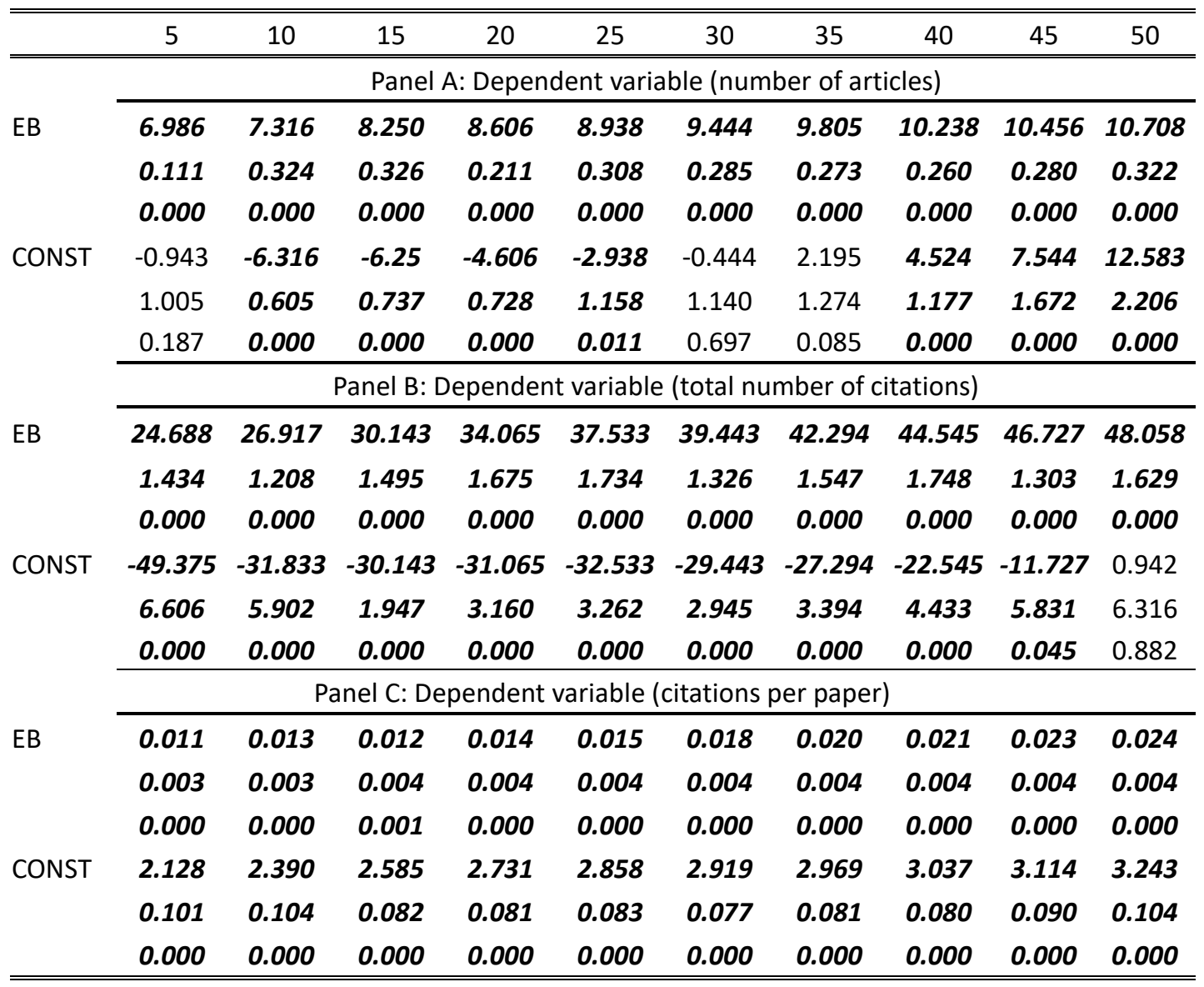

Note: For each of the quantiles, the following data are provided from top to bottom in each cell: the coefficient estimate, the standard error (1,000 bootstrapping replications), and the associated $P$ value (bold and italics denote $p$-values lower than $5 \%$ ). EB represents the number of editorial board members, CONST is a constant. 
Wang, $X$.

Table 4: Quantile Regression Estimates (Percentiles 50\%-95\%)

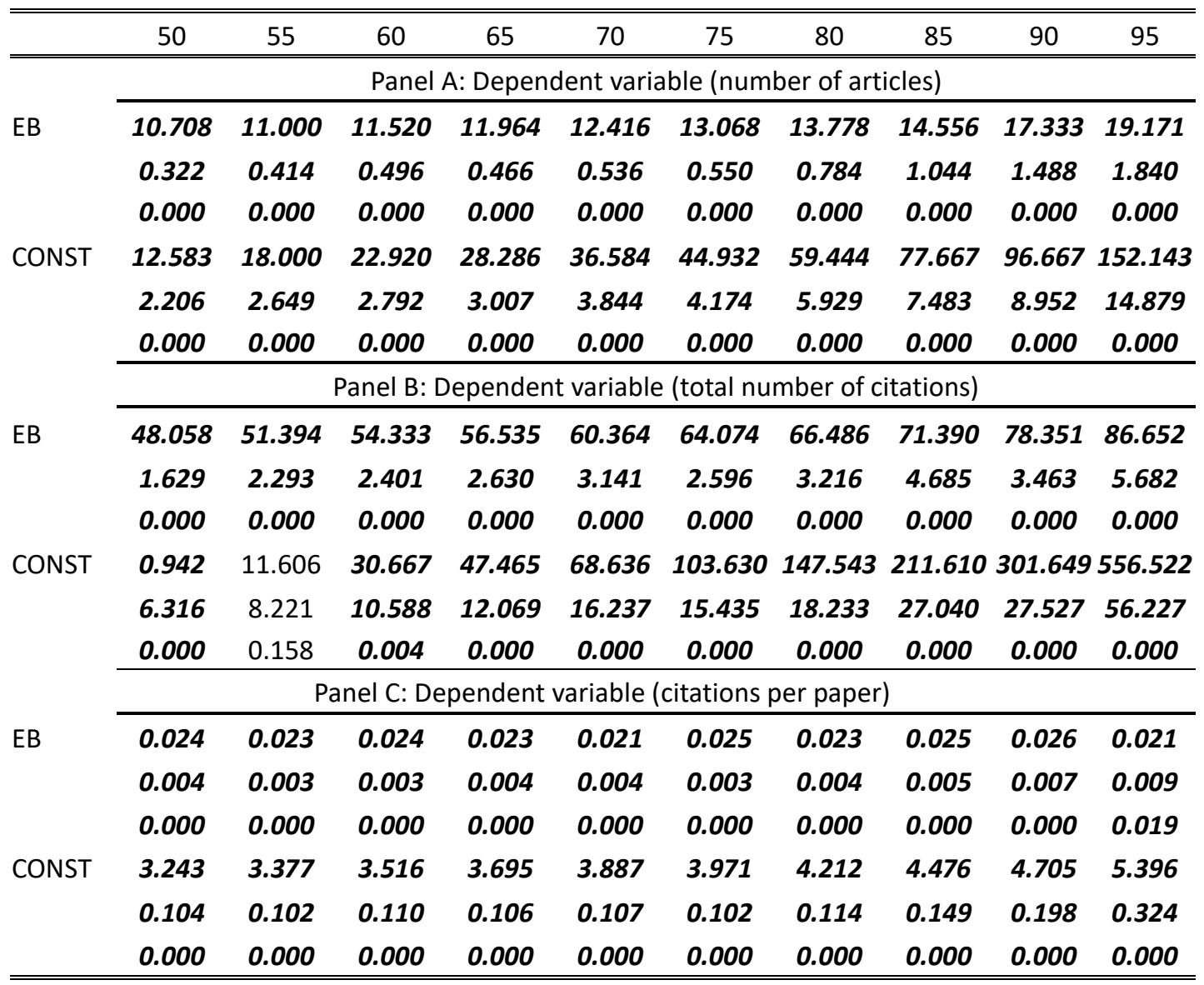

Note: For each of the quantiles, the following data are provided from top to bottom in each cell: the coefficient estimate, the standard error (1,000 bootstrapping replications), and the associated $P$ value (bold and italics denote $p$-values lower than $5 \%$ ). EB represents the number of editorial board members, CONST is a constant.

Figures 2 to 4 depict the quantile regression and OLS estimates. The editorial board coefficient of the quantile regression relating to the number of articles and total number of citations is above the mean estimate of the OLS models at higher quantiles, and under the mean estimate at lower quantiles. The OLS analysis underestimates the positive relationship between the number of editorial board members and the citations per paper for the $30 \%$ quantile and above. Thus, the quantile regression results reveal more information than the OLS models. 


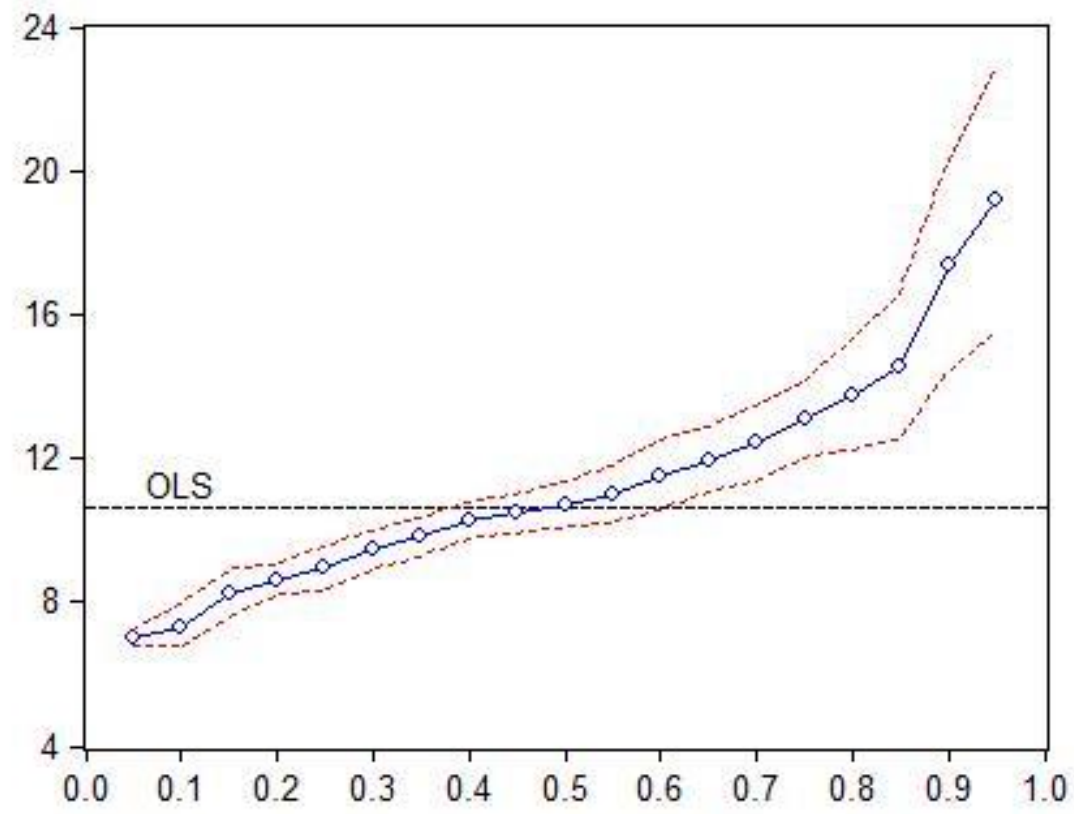

Figure 2: Coefficient Estimates for the Number of Articles, with 95\% Confidence Intervals

Note: The horizontal axis represents the quantile and the vertical axis shows the estimated parameter. The dashed horizontal line represents the OLS estimate. The estimated parameters of the quantile regression are displayed as circles. The $95 \%$ confidence intervals are displayed as dotted lines.

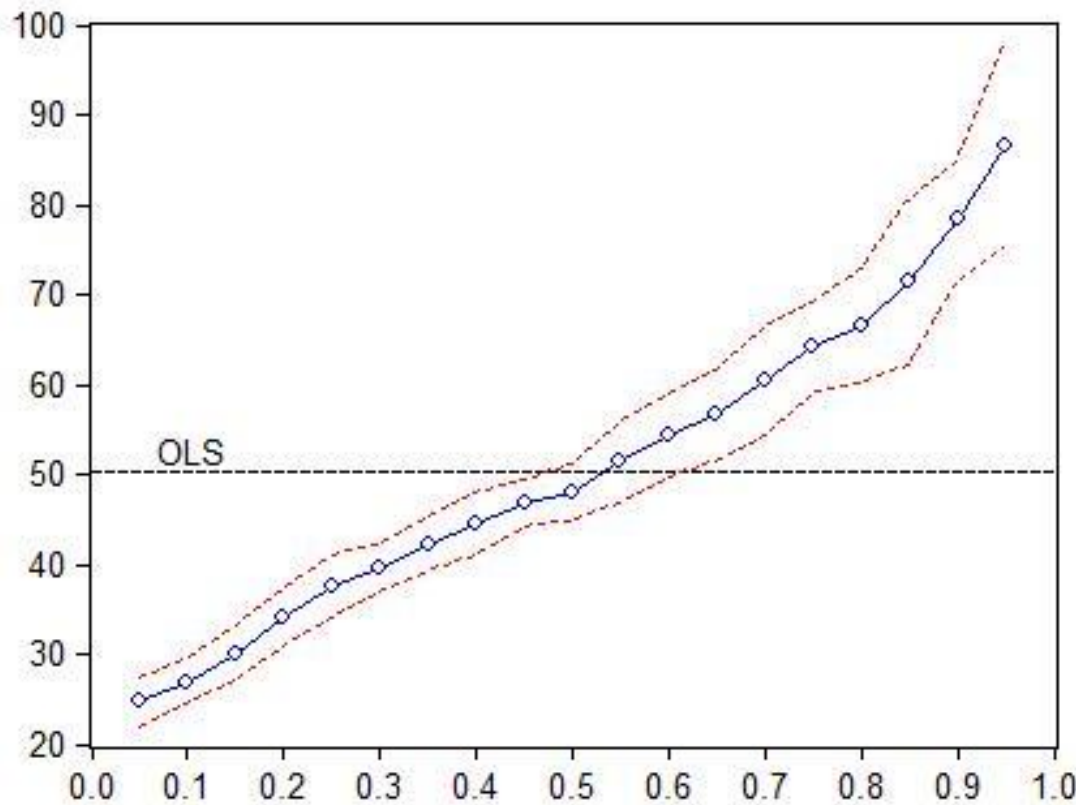

Figure 3: Coefficient Estimates for the Total Number of Citations, with 95\% Confidence Intervals.

Note: The horizontal axis represents the quantile and the vertical axis shows the estimated parameter. The dashed horizontal line represents the OLS estimate. The estimated parameters of the quantile regression are displayed as circles. The $95 \%$ confidence intervals are displayed as dotted lines. 


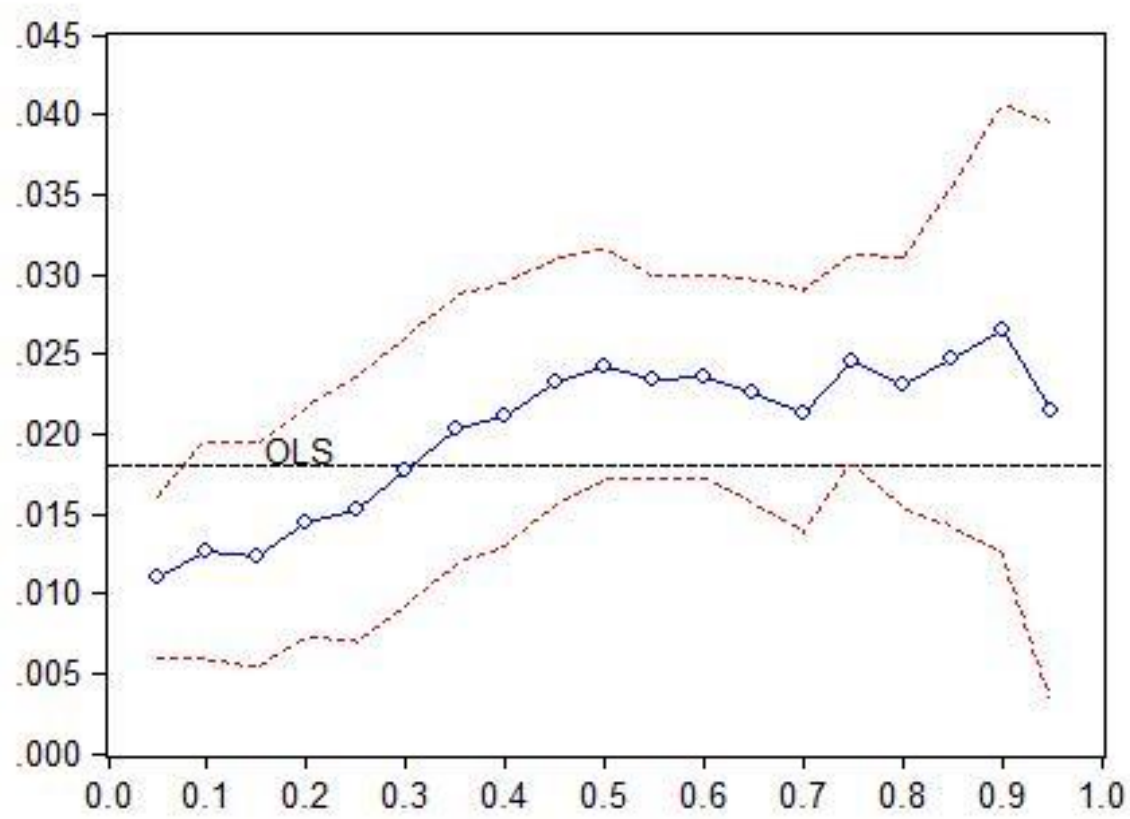

Figure 4: Coefficient Estimates for the Citations Per Paper, with 95\% Confidence Intervals

Note: The horizontal axis represents the quantile and the vertical axis shows the estimated parameter. The dashed horizontal line represents the OLS estimate. The estimated parameters of the quantile regression are displayed as circles. The $95 \%$ confidence intervals are displayed as dotted lines.

\section{DISCUSSIONS}

This study examined the relationship between $\mathrm{SCl}$ editorial board representation and the research output of universities in the field of computer science. It was found that the number of editorial board members is positively and significantly related to the quantity (number of articles) and impact (total number of citations and citations per paper) of the research output from their universities.

It should be noted that it was not intended to mean that there is a direct and causal relationship between editorial board representation and the research output from their universities. However, in this study, the researcher attempted to use two small samples to speculate on the possible mechanisms behind the relationship between editorial board representation and research output from their universities, and formed two possible conjectures: first, editorial board members may produce a substantial amount of high impact research for their universities on the basis of their outstanding scholarly achievements; second, editorial board members, considered the gatekeepers of scholarly journals, may have a certain influence on the research output of their universities by controlling the academic discourse. In terms of the first conjecture, a small sample was used to conduct an exploratory study at the individual level.

It was hypothesized that, if the editorial board members at a given university produce a substantial amount of high impact research for their universities, then the percentage of articles and citations produced by these editorial board members will exceed the percentage of editorial board members among all authors at that university. Moreover, the number of citations per article of the editorial board members at a given university will be 
higher than all authors of that university. This hypothesis was tested based on the following procedures:

a) The researcher used a purposive sampling method to select the five universities with the highest number of editorial board members, the four universities with the mean number of editorial board members, and the five universities with the fewest number of editorial board members (To reduce the error from those universities with a very small number of editorial board members, an arbitrary threshold of 10 members was set when selecting the five universities with the fewest number of editorial board members).

b) The researcher first extracted data regarding the research output of editorial board members of the sampled universities mentioned above from Web of Science. Then, the proportion of articles and citations produced by editorial board members for each sample university were calculated.

c) The researcher downloaded the articles published by the sample universities in the studied journals from the Web of Science for the years of 2008 to 2012. Then the number of authors for every sample university was counted according to the address information of authors and duplicate results were excluded. Finally, the percentage of editorial board members among all authors of every sample university was determined.

Table 5 presents the results of the exploratory analysis. It was found that both the percentage of articles and citations produced by editorial board members are significantly higher than the percentage of editorial board members among all authors for every sample university (Columns 3 and 4). However, when considering the comparison of citations per paper, the situation of every sample university is different: in nine of the sample universities, the citations per paper of editorial board members is higher than all authors of these universities, but in the other six sample universities, the situation is opposite (Columns 6 and 7). Overall, the difference in citations per paper between the editorial board members and all authors is not large: its absolute value is no more than 2 for most sample universities, excluding Rice University, University of Chile and University of Science and Technology - China.

Above all, in terms of the sample universities, editorial board members seem to make a certain contribution to the articles and total citations of their universities, but their contribution for citations per paper is not obvious and raises the question: Why are the citations per paper of editorial board members not as high as we expect? One possible reason is that authors without an editorship in computer science may be editorial board members in other related disciplines, such as applied mathematics or electrical engineering, and these authors may have high citations per article. Another possible reason is that serving on an editorial board leads to time and energy constraints, and some eminent researchers with high citations per paper may choose not to join an editorial board. However, the citations per paper of some editorial board members may simply be not very high. 
Wang, $X$.

Table 5: Contribution of Research Output by Editorial Board Members (EBM) from 15 Sample Universities

\begin{tabular}{|c|c|c|c|c|c|c|}
\hline University & $\begin{array}{l}\text { Number } \\
\text { of EBM }\end{array}$ & $\begin{array}{l}\text { Percent of } \\
\text { articles } \\
\text { produced } \\
\text { by EBM }\end{array}$ & $\begin{array}{l}\text { Percent of } \\
\text { citations } \\
\text { produced } \\
\text { by EBM }\end{array}$ & $\begin{array}{c}\text { Percent of } \\
\text { EBM } \\
\text { among all } \\
\text { authors } \\
\end{array}$ & $\begin{array}{l}\mathrm{Ci} / \mathrm{P} \text { of } \\
\mathrm{EBM}\end{array}$ & $\begin{array}{l}\mathrm{Ci} / \mathrm{P} \text { of all } \\
\text { authors }\end{array}$ \\
\hline Carnegie Mellon Univ. & 168 & 40.61 & 40.89 & 12.36 & 8.05 & 7.99 \\
\hline Georgia Inst Technol. & 116 & 35.13 & 33.30 & 8.32 & 8.69 & 9.17 \\
\hline Massachusetts Inst. Tech & 114 & 17.94 & 17.97 & 6.61 & 17.4 & 17.37 \\
\hline Natl. Univ. Singapore & 114 & 35.49 & 40.34 & 7.48 & 9.45 & 8.31 \\
\hline Stanford Univ. & 113 & 24.40 & 20.72 & 6.82 & 11 & 12.95 \\
\hline Univ. Texas Austin & 113 & 37.50 & 46.40 & 9.84 & 10.43 & 8.43 \\
\hline New Jersey Inst. Technol. & 27 & 43.75 & 51.87 & 9.83 & 11.3 & 9.53 \\
\hline Rice Univ. & 27 & 32.10 & 25.59 & 8.43 & 11.15 & 13.99 \\
\hline Univ. Sydney & 27 & 24.21 & 24.54 & 5.08 & 7.23 & 7.14 \\
\hline Yonsei Univ. & 27 & 26.05 & 28.37 & 3.83 & 5.86 & 5.38 \\
\hline $\begin{array}{l}\text { Manchester } \\
\text { Metropolitan Univ. }\end{array}$ & 10 & 22.81 & 17.54 & 11.11 & 4.62 & 6 \\
\hline Univ. Bari & 10 & 38.64 & 33.55 & 9.28 & 4.56 & 5.25 \\
\hline Univ. Chile & 10 & 27.66 & 45.94 & 4.62 & 9.74 & 5.86 \\
\hline Univ. Guelph & 10 & 43.31 & 49.05 & 7.41 & 7.49 & 6.61 \\
\hline $\begin{array}{l}\text { Univ. Sci. \& Technol. } \\
\text { China }\end{array}$ & 10 & $11.07 \%$ & $8.48 \%$ & $1.31 \%$ & 6.93 & 9.05 \\
\hline
\end{tabular}

Note: $\mathrm{EBM}=$ Editorial board members; $\mathrm{Ci} / \mathrm{p}=$ Citation per paper

In terms of the second conjecture, editorial board members are considered the gatekeepers of scholarly journals and control the academic discourse. García-Carpintero, Granadino and Plaza (2010, p.800) states that "The control of scientific journals is certainly one way in which the visibility and impact of specific research groups or communities can be made more visible". It was hypothesized that, if the editorial board members prefer to accept articles produced by their colleagues, the percentage of articles from institutions having editorial board members among all articles in a journal will be higher than the percentage of institutions having editorial board members among all institutions having articles in that journal (i.e. there is an over-representation of publications by authors from the same institutions in the journals where the institutions are represented in the editorial board). This hypothesis was tested based on the following procedures:

a) Sampling was purposive to include the top five journals (according to the impact factor of $2011 \mathrm{JCR}$ ) serving seven computer science sub-disciplines, that is, 24 journals (because some journals crossed disciplinary boundaries).

b) The researcher first extracted the articles from universities having editorial board members in every sample journal through Web of Science. Next, all articles published in every sample journal were extracted through Web of Science. Then, the percentage of articles from the institutions having editorial board members among all the articles in every sample journal was calculated.

c) After all articles published in every sample journal was obtained, the number of institutions having articles in every journal was counted by clicking the "Analyze Results" button. Next, the number of institutions having editorial board members in every sample journal was determined. Then the percentage of institutions having editorial board members among all the institutions having articles in every sample journal was calculated. The results are presented in Table 6. 
Table 6: Percentage of Articles from Institutions Having Editorial Board Members (EBM) among All Articles in a Journal Vs. The Percentage of Institutions Having EBM among All Institutions Having Articles in a Journal

\begin{tabular}{|c|c|c|c|c|}
\hline \multirow[t]{2}{*}{ Journal Titles } & \multicolumn{2}{|c|}{$\begin{array}{r}\text { Percentage of articles from } \\
\text { institutions having EBM } \\
\text { among all articles in a journal }\end{array}$} & \multicolumn{2}{|c|}{$\begin{array}{r}\text { Percentage of institutions } \\
\text { having EBM among all } \\
\text { institutions having articles in a } \\
\text { journal }\end{array}$} \\
\hline & $\mathrm{n}$ & $\%$ & $\mathrm{n}$ & $\%$ \\
\hline ACM COMPUT SURV & 12 & 12.63 & 14 & 8.05 \\
\hline ACM T GRAPHIC & 465 & 50.65 & 32 & 9.41 \\
\hline BIOL CYBERN & 88 & 29.63 & 29 & 7.84 \\
\hline ENTERP INF SYST-UK & 46 & 43.81 & 61 & 40.40 \\
\hline FOUND COMPUT MATH & 27 & 21.77 & 11 & 6.63 \\
\hline IEEE ACM T NETWORK & 380 & 53.98 & 46 & 19.57 \\
\hline IEEE COMMUN SURV TUT & 53 & 31.74 & 71 & 29.83 \\
\hline IEEE INTERNET COMPUT & 58 & 22.22 & 28 & 11.11 \\
\hline IEEE NETWORK & 28 & 14.43 & 23 & 9.16 \\
\hline IEEE T EVOLUT COMPUT & 95 & 34.55 & 37 & 10.85 \\
\hline IEEE T FUZZY SYST & 199 & 38.12 & 41 & 9.72 \\
\hline IEEE T HAPTICS & 50 & 40.00 & 16 & 8.70 \\
\hline IEEE T MED IMAGING & 454 & 52.18 & 52 & 17.05 \\
\hline IEEE T NEURAL NETWOR & 205 & 28.59 & 54 & 20.85 \\
\hline IEEE T PATTERN ANAL & 345 & 37.42 & 46 & 15.81 \\
\hline IEEE T VIS COMPUT GR & 239 & 25.16 & 22 & 8.00 \\
\hline IEEE WIREL COMMUN & 90 & 29.03 & 30 & 8.13 \\
\hline INT J NEURAL SYST & 30 & 16.39 & 30 & 11.90 \\
\hline J ACM & 69 & 47.59 & 25 & 15.15 \\
\hline J CHEM INF MODEL & 202 & 15.91 & 16 & 3.70 \\
\hline J STAT SOFTW & 108 & 32.63 & 54 & 14.96 \\
\hline MED IMAGE ANAL & 244 & 66.67 & 55 & 12.67 \\
\hline MIS QUART & 137 & 68.16 & 51 & 19.32 \\
\hline SIAM J IMAGING SCI & 87 & 43.07 & 35 & 13.67 \\
\hline
\end{tabular}

Note: $\mathrm{EBM}=$ Editorial board members.

For every sample journal, it was found that the percentage of articles from institutions having editorial board members among all articles in the journal is significantly higher than the percentage of institutions having editorial board members among all institutions having articles in the journal. However, it should be noted that the over-representation of publications by authors from the same institutions in journals where the institutions represented on the editorial board may be caused by many reasons. For example, it may simply be a function of high quality research: the articles from the institutions having editorial board members are of higher quality than articles from the institutions without editorial board members.

Why is the relationship between the number of editorial board members and the research output stronger (weaker) when the university is at the higher (lower) quantile of the conditional research output distribution? This could be attributed to research funding, research personnel input, and research policy - factors that generally affect a university's research output. Therefore, even if the number of editorial board members were the same at different universities, the influence of this variable on each university's research output could differ (e.g., the regression lines with different slopes shown in Figure 1). This indicates the existence of other possible influencing factors, such as research input or research policy. For example, in China, some research universities offer considerable cash 
bonuses to encourage their faculty members to publish in top $\mathrm{SCl}$ and $\mathrm{SSCl}$ (Social Science Citation Index) journals. Additionally, having a certain number of $\mathrm{SCl}$ papers is often used as a rigid regulation for obtaining a Ph.D. degree in China. These research policies may result in more articles being published from such universities. The difference between universities in research input or research policies may be the cause of the difference in the relation between the number of editorial board members and research output when the universities locate at different conditional research output distribution quantiles. It is possible that universities that invest more (less) in scientific research and have more (less) powerful research policy are more likely to be located at the higher (lower) quantile of the conditional distribution of research output. Because it is difficult to acquire the research input data and research policies of universities in a single discipline, these factors were not included in the model of this study.

\section{CONCLUSION}

In this study, the relationship between $\mathrm{SCl}$ editorial board representation and the research output of universities in the field of computer science was examined. The empirical results indicated that the number of editorial board members is positively and significantly related to the quantity (number of articles) and impact (total number of citations and citations per paper) of the research output from their universities. More importantly, quantile regressions was used to observe that (a) the relationship between the number of editorial board members, and the number of articles is stronger (weaker) when the university is at the higher (lower) quantile of the number of articles distribution; (b) the relationship between the number of editorial board members and the total number of citations is also stronger (weaker) when the university is at the higher (lower) quantile of the total number of citations distribution; and (c) the coefficient of number of editorial board members on the citations per paper also shows an overall increasing trend, though the increase is less obvious after the $50 \%$ quantile. The quantile regressions revealed information that was not observable with OLS regression models.

There are some limitations to note, which also suggest directions for future research. First, in the computer science discipline, conference proceedings are an important publication venue. Future research could examine the relationship between gatekeepers of conferences and research output based on conference proceedings. Second, the empirical results presented are limited to the computer science discipline. More studies are needed to investigate whether the conclusions made in this study could be extended to other disciplines. Finally, although two small samples were used to speculate on possible mechanisms behind the relationship between editorial board representation and research output from their universities, causal mechanisms require additional research using designs that accommodate temporal order and more samples.

\section{ACKNOWLEDGEMENT}

This research was supported by MOE (Ministry of Education in China) Project of Humanities and Social Science (Project No. 17YJCZH179). 


\section{REFERENCES}

Asnafi, S., Gunderson, T., McDonald, R. J., and Kallmes, D. F. 2017. Association of h-index of editorial board members and impact factor among radiology journals. Academic Radiology, Vol. 24, no. 2: 119-123.

Bošnjak, L., Puljak, L., Vukojević, K., and Marušić, A. 2010. Analysis of a number and type of publications that editors publish in their own journals: Case study of scholarly journals in Croatia. Scientometrics, Vol. 86, no. 1: 227-233.

Braun, T., and Dióspatonyi, I. 2005a. The counting of core journal gatekeepers as science indicators really counts. The scientific scope of action and strength of nations. Scientometrics, Vol. 62, no. 3: 297-319.

Braun, T., and Dióspatonyi, I. 2005b. Counting the gatekeepers of international science journals a worthwhile science indicator. Current Science, Vol. 89, no. 9: 1548-1551.

Braun, T., and Dióspatonyi, I. 2005c. Gatekeeping indicators exemplified by the main players in the international gatekeeping orchestration of analytical chemistry journals. Journal of the American Society for Information Science and Technology, Vol. 56, no. 8: 854-860.

Braun, T., Dióspatonyi, I., Zádor, E., and Zsindely, S. 2007. Journal gatekeepers indicatorbased top universities of the world, of Europe and of 29 countries - A pilot study. Scientometrics, Vol. 71, no. 2: 155-178.

Braun, T., Dióspatonyi, I., Zsindely, S., and Zádor, E. 2007. Gatekeeper index versus impact factor of science journals. Scientometrics, Vol. 71, no. 3: 541-543.

Burgess, T. F., and Shaw, N. E. 2010. Editorial board membership of management and business journals: A social network analysis study of the financial times 40 . British Journal of Management, Vol. 21, no. 3: 627-648.

Chan, K. C., and Fok, R. C. W. 2003. Membership on editorial boards and finance department rankings. Journal of Financial Research, Vol. 26, no. 3: 405-420.

Chan, K. C., Fung, H.-G., and Lai, P. 2005. Membership of editorial boards and rankings of schools with international business orientation. Journal of International Business Studies, Vol. 36, no. 4: 452-469.

Cole, J. R., and Cole, S. 1973. Social stratification in science. Chicago: University of Chicago Press.

Danell, R. 2011. Can the quality of scientific work be predicted using information on the author's track record? Journal of the American Society for Information Science and Technology, Vol. 62, no. 1: 50-60.

Frandsen, T. F., and Nicolaisen, J. 2011. Praise the bridge that carries you over: Testing the flattery citation hypothesis. Journal of the American Society for Information Science and Technology, Vol. 62, no. 5: 807-818.

Frey, B. S., and Rost, K. 2010. Do rankings reflect research quality? Journal of Applied Economics, Vol. 13, no. 1: 1-38.

García-Carpintero, E., Granadino, B., and Plaza, L. M. 2010. The representation of nationalities on the editorial boards of international journals and the promotion of the scientific output of the same countries. Scientometrics, Vol. 84, no. 3: 799-811.

Gibbons, J. D., and Fish, M. 1991. Rankings of economics faculties and representation on editorial boards of top journals. Journal of Economic Education, Vol. 22, no. 4: 361-366.

Kaufman, G. G. 1984. Rankings of finance department by faculty representation on editorial boards of professional journal: A note. Journal of Finance, Vol. 39, no. 4: 11891195.

Kay, J., Memon, M., de Sa, D., Simunovic, N., Duong, A., Karlsson, J., and Ayeni, O. R. 2017. The h-index of editorial board members correlates positively with the impact factor of 
sports medicine journals. Orthopaedic Journal of Sports Medicine, Vol. 5, no. 3: 232596711769402.

Koenker, R., and Bassett, G. 1978. Regression quantiles. Econometrica, Vol. 46, no. 1: 3350.

Kumar, V., and Srivastava, R. 2013. Indian gatekeepers of foreign journals: A preliminary analysis. Journal of Scientometrics Research, Vol. 2, no. 2: 110-115.

Langer, L. L., and Frensch, P. A. 1999. Gaining scientific recognition by position: Does editorship increase citation rates? Scientometrics, Vol. 44, no. 3: 459-486.

Law, R., Leung, R., and Buhalis, D. 2010. An analysis of academic leadership in hospitality and tourism journals. Journal of Hospitality \& Tourism Research, Vol. 34, no. 4: 455-477.

Levy, H., Huang, Y., Wolf, A., and Wolf, Y. 2014. Editor citation: An alleged instance of social-professional desirability. Journal of Scientometric Research, Vol. 3, no. 1: 46-56.

Luty, J., Arokiadass, S. M. R., Easow, J. M., and Anapreddy, J. R. 2009. Preferential publication of editorial board members in medical specialty journals. Journal of Medical Ethics, Vol. 35, no. 3: 200-202.

Mani, J., Makarević, J., Juengel, E., Ackermann, H., Nelson, K., Bartsch, G., Haferkamp, A., and Blaheta, R. A. 2013. I publish in I edit? - Do editorial board members of Urologic journals preferentially publish their own scientific work? PLoS ONE, Vol. 8, no. 12: e83709.

Pardeck, J. T., and Meinert, R. G. 1999. Scholarly achievements of the social work editorial board and consulting editors: A commentary. Research on Social Work Practice, Vol. 9, no. 1: 86-91.

Sugimoto, C. R., and Cronin, B. 2012. Citation gamesmanship: Testing for evidence of ego bias in peer review. Scientometrics, Vol. 95, no. 3: 851-862.

Urbancic, F. R. 2005. Faculty representation of the editorial boards of leading marketing journals: An update of marketing department. Marketing Education Review, Vol. 15, no. 2: 61-69.

Urbancic, F. R. 2011. The gatekeepers of business education research: An institutional analysis. Journal of Education for Business, Vol. 86, no. 5: 302-310.

Valle, M., and Schultz, K. 2011. The etiology of top-tier publications in management. Career Development International, Vol. 16, no. 3: 220-237.

Walters, W. H. 2015. Do editorial board members in library and information science publish disproportionately in the journals for which they serve as board members? Journal of Scholarly Publishing, Vol. 46, no. 4: 343-354.

Walters, W. H. 2016. The research contributions of editorial board members in library and information science. Journal of Scholarly Publishing, Vol. 47, no. 2: 121-146.

White, H. 1980. A heteroskedasticity-consistent covariance matrix estimator and a direct test for heteroskedasticity. Econometrica, Vol. 48, no. 4: 817-838.

Wolf, Y., Levy, H., Huang, Y., and Wolf, A. 2014. Editor citation: An alleged instance of social-professional desirability. Journal of Scientometric Research, Vol. 3, no. 1: 46.

Zhang, L., and Jiang, C. 2015. Social network analysis and academic performance of the editorial board members for journals of library and information science. COLLNET Journal of Scientometrics and Information Management, Vol. 9, no. 2: 131-143.

Zsindely, S., Schubert, A., and Braun, T. 1982. Editorial gatekeeping patterns in international science journals. A new science indicator. Scientometrics, Vol. 4, no. 1: 5768. 